\title{
PERSEPSI GENERASI MUDA SUKU BATAK DI KELURAHAN SIMPANG BARU KOTA PEKANBARU TERHADAP TRADISI
}

\section{MARTAROMBO}

\author{
Grace Octaviani $^{1}$, Isjoni ${ }^{2}$, Asyrul Fikri ${ }^{3}$. \\ Email: graceharianja.gh@gmail.com,isjoni@yahoo.com, \\ asyrul.fikri@lecturer.unri.ac.id \\ Universitas Riau, Pekanbaru \\ Cp : 082172845094
}

\begin{abstract}
ABSTRAK
Penelitian ini bertujuan untuk mengetahui persepsi generasi muda suku Batak terhadap tradisi martarombo di Kelurahan Simpang Baru Kota Pekanbaru. Tradisi Martarombo merupakan salah satu tradisi suku Batak yang dilakukan untuk mengetahui kekerabatan antar suku Batak. Sudah menjadi kewajiban bagi masyarakat suku Batak untuk mengetahui silsilahnya agar mengetahui letak hubungan kekerabatan dengan orang lain. Penelitian ini menggunakan metode deskriptif dengan pendekatan kuantitatif dengan jumlah populasi 500 generasi muda suku Batak yang merupakam amggota dari setiap organisasi marga yang ada di Kelurahan Simpang Baru, pengambilan sampel dalam penelitian ini menggunakan tehnik kuota yaitu $10 \%$ dari 500, sehingga jumlah sampel sebanyak 50 responden dengan pengambilan sampel secara insidental (kebetulan). Selain itu dilakukan wawancara kepada setiap ketua Badan Pengurus Harian (BPH) organisasi marga yang ada di Kelurahan Simpang Baru. Hasil penelitian ini menunjukan bahwa generasi muda suku Batak di Kelurahan Simpang Baru dengan pemahaman baik ada 8 orang, berpemahaman sedang dengan jumlah 36 orang, berpemahaman buruk 6 orang. Sementara generasi muda yang berpenerapan baik ada 10 orang, yang berpenerapan sedang ada 31 orang, yang berpenerapan buruk ada 9 orang, dan generasi muda yang berpersepsi baik ada 10 orang, berpersepsi sedang ada 29 orang dan yang berpersepsi buruk ada 11 orang. Berdasarkan hasil analisis penelitian ini, kesimpulan yang didapatkan yaitu responden setuju dengan adanya pelaksanaan tradisi martarombo di perantauan, selain pelestarian budaya melalui tradisi ini juga dapat memperkuat hubungan persaudaraan dengan sesama.
\end{abstract}

\section{Kata Kunci : Persepsi, Tradisi martarombo, Suku Batak}

\section{ABSTRACT}

This study aims to determine the young generation of Batak tribe's perception towards the martarombo tradition in Simpang Baru Village, Pekanbaru City. The Martarombo Tradition is one of the Batak traditions performed to determine the relationship between the Batak tribes. It is an obligation for the Batak people to know their family trees to know the location of kinship with other people. This study used a descriptive method with a quantitative approach with a population of 500 young people of the Batak tribe who are members of each clan organization 
Persepsi Generasi Muda Suku Batak di Kelurahan Simpang Baru Kota Pekanbaru Terhadap

Tradisi Martarombo

(Grace Octaviani, Isjoni, Asyrul Fikri)

in Simpang Baru Village, the sample in this study used a quota technique of $10 \%$ of 500, so the sample size was 50 respondents. by occasional sampling. In addition, interviews were conducted with each head of the Daily Executive Board (BPH) of clan organizations in Simpang Baru Village. The results of this study indicate that there are 8 people with a good understanding of the Batak ethnic youth in Simpang Baru Village, 36 people with a moderate understanding and 6 people with a poor understanding. Meanwhile, there are 10 young people with good practices, 31 people with moderate practices, 9 people with bad perceptions and 10 people with good perceptions, 29 people with moderate perceptions and 11 people with bad perceptions. Based on the results of the analysis of this study, it is concluded that the respondents agree with the implementation of the martarombo tradition in overseas countries, besides cultural preservation through this tradition, it can also strengthen fraternal relationships with others.

\section{Keywords: Perception, Martarombo Tradition, Batak Tribe}

\section{PENDAHULUAN}

Budaya merupakan identitas yang menunjukkan karakter seseorang yang memilikinya dan membedakannya dari orang lain, baik itu dari segi kebiasaan hidup, adat istiadat, bahasa daerah (Budi Santoso, 2006:45). Indonesia memiliki beraneka ragam suku dan budaya. Salah satu bentuk keragaman suku yang ada di Indonesia yaitu Suku Batak. Suku Batak adalah penduduk asli di Provinsi Sumatera Utara, secara khusus suku Batak terdiri dari enam sub suku yaitu Toba, Karo, Simalungun, Pakpak, Angkola dan Mandailing (Sugiyarto, 2015:35).

Suku Batak memiliki kekayaan budaya yang mengatur kehidupan masyarakatnya. Hal ini tampak dari adanya tulisan dan bahasa sendiri dengan perbendaharaan kata yang sangat lengkap, serta adat istiadat yang khas dan spesifik yang membedakannya dengan suku bangsa yang lain. Sejalan dengan hal tersebut Armaidy Armawi (2008:158), mengatakan salah satu budaya yang menjadi kebanggan masyarakat Batak Toba salah satunya yaitu sistem hubungan sosial dalihan na tolu yang terwujud dalam hubungan kekerabatan berdasarkan keturunan darah (genealogis) dan perkawinan yang berlaku secara turun-temurun hingga saat ini.

Sebagai sistem budaya, prinsip dalihan na tolu sudah ada sejak dahulu dan dijadikan hukum adat berfungsi sebagai pedoman yang mengatur, mengendalikan dan memberi arah kepada tata laku (perilaku) dan perbuatan (sikap atau pola tingkah laku) masyarakat suku Batak Toba. Dalam prinsip inilah orang Batak 
Toba Bersosialisasi dengan sesama sukunya membentuk sistem sosial yang baik, sehingga orang Batak juga dituntut untuk mengetahui silsilah atau tarombo (Basyral Harahap dan Hotman Siahaan, 1987:3).

Silsilah Batak atau disebut tarombo Batak adalah silsilah garis keturunan yang diambil secara patrilineal. Silsilah dalam orang Batak dapat diketahui melalui aktivitas martarombo atau aktivitas mencari hubungan kekerabatan (partuturan). Hubungan kekerabatan ini diwujudkan dalam bentuk sistem marga (klen). Nama marga yang dimiliki oleh setiap keluarga batak diambil dari nama $\mathrm{Si}$ Raja Batak yang kemudian mempunyai keturunan dan berkembang menjadi marga-marga dalam suku Batak (Billy Pranata, 2019:17).

Menurut Toga Sihombing (1986:103), Martarombo dilakukan ketika masyarakat Batak ingin mengetahui seluk beluk persaudaraan atau hubungan kekerabatan yang terjalin diantara sesama orang Batak ketika bertemu baik dalam kegiatan adat maupun kehidupan sehari-hari yang ditentukan melalui marga. Martarombo dan marga tersebut sangat berhubungan dalam menentukan status dan peran seorang individu dalam sistem sosial masyarakat Batak Toba.

Silsilah (tarombo) baik dari garis keturunan ayah maupun ibu penting diketahui ketika melakukan kegiatan martarombo. Karena pada dasarnya ketika martarombo orang akan menyebutkan dua marga, yakni marganya sendiri dan marga ibunya. Apabila seorang berjumpa dengan satu marganya maka akan terjalin persaudaraan yang sangat dalam. Apabila tidak satu marga pun tarombo akan dilanjutkan oleh marga ibunya, atau marga neneknya hingga dapat menentukan partuturan yang tepat diantara mereka (Bungaran Simanjuntak, 2011:223).

Partuturan (tutur sapa) bagi masyarakat Batak Toba sebagai satu kesponanan untuk menghargai dan menghormati orang lain. Salah satu makna kesopanan yang terdapat dalam tutur tersebut yaitu tidak semua orang dapat disebut namanya walaupun usianya lebih muda dari kita, tetapi harus menggunakan sebutan tutur sebagai simbol atau tanda pertalian hubungan kekeluargaan diantara masyarakat (Sahrudin Pohan, 2019:353).

Namun generasi muda yang ada saat ini baik di kota maupun di desa telah mengalami masa modernisasi. Biarpun berada didesa sedikit banyaknya 
Persepsi Generasi Muda Suku Batak di Kelurahan Simpang Baru Kota Pekanbaru Terhadap Tradisi Martarombo

(Grace Octaviani, Isjoni, Asyrul Fikri)

pengetahuan tentang dunia luar akan mempengaruhi pengetahuan masyarakat. Hildangris Nahak (2019:67) mengatakan pelestarian budaya sangat penting untuk dipahami meskipun banyak akulturasi yang masuk, dengan menjaga dan selalu menerapkan nilai budaya yang ada dalam martarombo dalam kegiatan sehari-hari akan mencerminkan pemahaman terhadap falsafah tersebut.

Dengan menyadari arti penting tradisi martarombo bagi masyarakat Batak serta pelestarian budaya bagi generasi yang akan datang. Maka dari itu penulis tertarik melakukan penelitian mengenai "Persepsi Generasi Muda Suku Batak Di Kelurahan Simpang Baru Kota Pekanbaru Terhadap Tradisi Martarombo". Tujuan penelitian ini yaitu: (1) Mengetahui pemahaman generasi muda suku Batak terhadap tradisi martarombo di Kelurahan Simpang Baru Kota Pekanbaru (2) Mengetahui penerapan tradisi martarombo di kalangan generasi muda suku Batak (3) Mengetahui persepsi generasi muda suku Batak terhadap tradisi martarombo.

\section{TINJAUAN PUSTAKA}

\section{Kebudayaan}

Selo Soemardjan dan Soelaeman Soemardi (1947:113), menyebutkan kebudayaan itu adalah semua hasil karya, rasa dan cipta masyarakat. Karya masyarakat menghasilkan teknologi dan kebudayaan kebendaan atau kebudayaan jasmaiah (material culture) yang diperlukan oleh manusia untuk menguasai alam sekitarnya agar kekuatan serta hasilnya dapat diabadikan untuk keperluan masyarakat. Menurut Koentjaraningrat dalam Dewi Yuliati (2007:1) kebudayaan mempunyai tiga wujud yaitu : (1) Wujud kebudayaan sebagai kompleks gagasan, konsep dan pemikiran manusia, (2) Wujud kebudayaan sebagai suatu kompleks aktivitas, (3) Wujud kebudayaan sebagai benda.

\section{Persepsi Generasi Muda}

Generasi muda erat hubungannya dengan arti generasi muda sebagai generasi penerus. Secara etimologi berasal dari dua kata yaitu generasi yang berarti angkatan atau turunan dan muda yang berarti belum lama ada. Generasi muda berarti angkatan atau turunan yang belum lama hidup (Afriantoni, 2015:49).

Generasi muda disebut sebagai agent of change, karena ciri yang melekat pada kemudaan mereka yaitu, energik, kreatif, dinamis, emoatik, kritis dan berani 
mengambil resiko. Batasan generasi muda dapat dilihat dari aspek usia, namun usia tidak menjadi jaminan mutlak bagi suatu generasi giat bekerja atau tidak. Kata pemuda dipakai untuk memberikan generalisasi kepada masyarakat dalam golongan usia tertentu seperti anak-anak dan golongan tua (H.E Sumantri, 2014:15). Generasi muda yang dimaksud dalam penelitian ini adalah mahasiswa yang berada di Kelurhan Simpang Baru Kota Pekanbaru.

Menurut Rakhmat dalam Hadi Arifin (2018:90), persepsi adalah pengalaman tentang objek, peristiwa atau hubungan-hubungan yang diperoleh dengan menyimpulkan informasi dan menafsirkan peran dan yang akan memberikan makna pada stimuli inderawi.

Persepsi terjadi pada saat seseorang akan menyeleksi situasi dan kondisi yang hidup disekitarnya. Persepsi dapat diartikan sebagai proses mengetahui atau mengenali objek dan kejadian objektif dengan bantuan indera cara pandang. Dapat disimpulkan bahwa, persepsi generasi muda merupakan proses perlakuan generasi muda terhadap suatu objek yang terjadi di dalam lingkungan sekitar melalui pengamatan dengan indera yang dimiliki.

\section{Tradisi Martarombo}

Tarombo dalam suku Batak Toba merupakan silsilah asal-usul serta penyebaran marga-marga yang terdapat pada masyarakat Batak. Secara umum masyarakat Batak dalam sosialisasinya sering membicarakan silsilah marganya pada setiap kesempatan, dengan tujuan untuk mengetahui hubungan kekerabatan dan kekeluargaan pada orang yang diajak martarombo. Dengan melihat tarombo dapat mempermudah menentukan kaitan kekerabatan seseorang dengan orang lain dalam satu marga (A Marbun dan T Hutapea, 1987:173).

Dengan mengetahui martarombo seseorang dapat dengan segera menentukan posisinya dalam marganya sendiri maupun posisinya dalam hubungannya dengan marga-marga Batak lainnya. Kegiatan martarombo yang biasanya dilakukan yaitu dengan menanyakan dan memberitahukan marga, nomor keturunan (pomparan), asal daerah hingga menentukan hubungan kekerabatan dan partuturan yang tepat. 
Persepsi Generasi Muda Suku Batak di Kelurahan Simpang Baru Kota Pekanbaru Terhadap Tradisi Martarombo

(Grace Octaviani, Isjoni, Asyrul Fikri)

\section{METODE PENELITIAN}

Penelitian ini menggunakan jenis penelitian deskriptif dan menggunakan metode penelitian kuantitatif. Dimana yang dikumpulkan di lakukan untuk mengetahui penilaian dari responden serta mendeskriptifkan tanggapan persepsi generasi muda di lapangan atas pertanyaan pertanyaan di dalam kuesioner (Abu Ahmadi, 2010:76. Teknik Analisis di gunakan dengan cara : Data Kualitatif yang diolah menggunakan spss serta mendeskriptifkan melalui kata kata dan tabel.

Penelitian ini dilakukan di Kelurahan Simpang Baru, Kecamatan Tampan, Kota Pekanbaru Provinsi Riau. Di Kelurahan Simpang Baru ini terdapat 16 orgaisasi paguyuban marga yang dapat ditemukan. Kelurahan Simpang Baru memiliki luas wilayah $6,4 \mathrm{Km}^{2}$ dengan peesentasi $10,7 \%$. Kelurahan Simpang Baru yang berada dalam wilayah kecamatan Tampan ini memiliki batas-batas wilayah sebagai berikut: (a) Sebelah utara berbatasan dengan desa Labuh Baru Barat (kecamatan Payung Sekaki) (b) Sebelah selatan berbatasan dengan kelurahan Tuah Karya. (c) Sebelah barat berbatasan dengan kabupaten Kampar. (d) Sebelah timur berbatasan dengan kelurahan Delima (Dokumen Kelurahan Simpang Baru, 2020).

Untuk mendapatkan data peneliti menggunakan angket yang berisi pertanyaan mengenai masalah ataupun bidang yang akan diteliti. Jenis angket yang digunakan dalam penelitian ini adalah angket tertutup, mengumpulkan data dengan melaksanakan wawancara langsung kepada informan. Informan dalam penelitian ini adalah Badan Pengurus Harian (BPH) setiap organisasi marga yang ada di kelurahan Simpang Batu Kota Pekanbaru, mengumpulkan data melalui dokumentasi dan observasi.

Populasi yang digunakan dalam penelitian ini adalah mahasiswa suku Batak yang merupakan anggota setiap organisasi marga yang tersebar di Kelurahan Simpang Baru Kota Pekanbaru yaitu berjumlah 500 orang. Penarikan sampel yang digunakan dalam penelitian ini diambil secara kuota (Anna Armeini, 2017:64), karena generasi muda yaitu mahasiswa suku Batak berasal dari kultur yang sama dan bersifat homogen. Jumlah sampel yang diambil yakni $10 \%$ dari 500 jumlah mahasiswa, sehingga jumlah sampel sebanyak 50 orang. 
Penentuan sampel setiap organisasi marga ditentukan secara proporsional sebagai berikut :

$$
S=\frac{P}{N} \times P
$$

Di mana :

S : Sampel

P : Jumlah mahasiswa perorganisasi

$\mathrm{N}$ : Berasaran Populasi

Pemilihan sampel dalam penelitian ini dilakukan dengan tehnik insidental atau kebetulan, yaitu siapa saja anggota populasi yang kebetulan ditemui dan yang mau diteliti oleh peneliti pada saat itu (Anna Armeini, 2017:61).

\section{HASIL DAN PEMBAHASAN}

\section{Pemahaman Generasi Muda Terhadap Tradisi Martarombo}

Pemahaman generasi muda terhadap tradisi martarombo dapat dilihat bedasarkan hasil penelitian yang dilakukan secara umum kepada 50 sampel, yang terdiri dari anggota-anggota setiap organisasi marga yang ada di Kelurahan Simpang Baru Kota Pekanbaru. Agar lebih jelas dapat dilihat pada tabel berikut ini :

\begin{tabular}{|c|l|c|c|}
\hline No & \multicolumn{1}{|c|}{ Kategori } & Frekuensi (Jiwa) & Persentasi (\%) \\
\hline 1. & Berpemahaman Tinggi & 8 & 16,0 \\
\hline 2. & Berpemahaman Sedang & 36 & 72,0 \\
\hline 3. & Berpemahaman Rendah & 6 & 12,0 \\
\hline \multicolumn{2}{|c|}{ Total } & 50 & 100,0 \\
\hline
\end{tabular}

Sumber : Kuisioner Penelitian Tahun 2020

Berdasarkan tabel tersebut dapat dilihat bahwa sebagian besar responden berpemahaman sedang sebanyak 36 jiwa dengan persentase $72,0 \%$, Hal ini dibuktikan bahwa dengan usia yang masih muda sebagian besar dari mereka sudah memahami tujuan dan tata cara tradisi martarombo, mengetahui silsilah marganya dan lain-lain. Pemahaman terhadap tradisi ini sudah menjadi sebuah keharusan bagi setiap generasi muda suku Batak yang nantinya akan melanjutkan tradisi ini ke generasi selanjutnya. 
Persepsi Generasi Muda Suku Batak di Kelurahan Simpang Baru Kota Pekanbaru Terhadap Tradisi Martarombo

(Grace Octaviani, Isjoni, Asyrul Fikri)

\section{Penerapan Generasi Muda Terhadap Tradisi Martarombo}

Berdasarkan tabel berikut ini terlihat bahwa 31 responden dengan persentase $72,0 \%$ berpenerapan sedang, artinya sebagian besar dari generasi muda suku Batak di Kelurahan Simpang Baru sudah melaksanakan tradisi martarombo ini dengan baik, meskipun ada yang tidak memberikan informasi secara terbuka kepada lawan bicara. Mencari informasi mengenai partuturan dengan seseorang menjadi salah satu hal yang penting untuk dapat memulai pembicaraan agar kita dapat mengetahui hubungan kekerabatan sehingga bertutur dapat berjalan dengan baik diantara dua individu.

\begin{tabular}{|c|l|c|c|}
\hline No & \multicolumn{1}{|c|}{ Kategori } & Frekuensi (Jiwa) & Persentasi (\%) \\
\hline 1. & Penerapan Baik & 10 & 16,0 \\
\hline 2. & Penerapan Sedang & 31 & 72,0 \\
\hline 3. & Penerapan Rendah & 9 & 12,0 \\
\hline \multicolumn{2}{|c|}{ Total } & 50 & 100,0 \\
\hline
\end{tabular}

Sumber : Kuisioner Penelitian Tahun 2020

\section{Persepsi Generasi Muda Terhadap Tradisi Martarombo}

Berdasarkan tabel dibawah ini terlihat bahwa responden terbanyak dengan persepsi sedang terdapat 29 jiwa dengan persentase 58,0\%. Hal ini dibuktikan dari sebagian besar generasi muda suku Batak memahami sebagian besar tradisi martarombo dan dapat melaksanakannya tradisi martarombo dengan baik.

\begin{tabular}{|c|l|c|c|}
\hline No & \multicolumn{1}{|c|}{ Kategori } & Frekuensi (Jiwa) & Persentasi (\%) \\
\hline 1. & Berpersepsi Baik & 10 & 20,0 \\
\hline 2. & Berpersepsi Sedang & 29 & 58,0 \\
\hline 3. & Berpersepsi Buruk & 11 & 22,0 \\
\hline \multicolumn{2}{|c|}{ Total } & 50 & 100,0 \\
\hline
\end{tabular}

Sumber : Kuisioner Penelitian Tahun 2020

\section{KESIMPULAN}

Masyarakat Batak Toba khusnya generasi muda Masyarakat Batak Toba khususnya generasi muda yang ada di Kelurahan Simpang Baru Kota Pekanbaru Provinsi Riau sudah cukup mengetahui dan mengerti apa tradisi martarombo itu, 
Pemahaman tentang tradasi martarombo didapatkan sejak kecil. Meskipun zaman semakin modern tetapi mereka masih tertarik untuk memperlajari asal usul marganya serta di sosialisasikan ke berbagai komunitas suku Batak melalui tradisi martarombo. Melalui tradisi martarombo ini dapat menjalin hubungan kekeluargaan yang baru dimana pun dan kapan pun berada.

\section{DAFTAR PUSTAKA}

Adison Sihombing. "Mengenal Budaya Batak Toba Melalui Falsafah "Dalihan $\mathrm{Na}$ Tolu” : Perspektif Kohesi dan Kerukunan. Jurnal Lektur Keagamaan. Vol 16, No 2. 2018. Hal 350.

Ahmadi, Abu. 2010. Metodologi Penelitian. Jakarta : Bumi Aksara.

Afriantoni. 2015. Prinsip-Prinsip Pendidikan Ahlak Generasi Muda. Yogyakarta : Budi Utama.

Armaidy Armawi.'Kearifan Lokal Batak Toba Dalihan Na Tolu dan Good Governance Dalam Birokrasi Publik". Jurnal Filsafat. Vol 18, No 2, 2008. Hal 158.

Armeini, Anna. 2017. Statistika Inferensial :Untuk Psikologi dan Pendidikan. Jakarta : Kakilangi Kencana.

Billy Pranata . 'Perancangan Sistem Penyusunan Marga Suku Batak Toba Berbasis Web". Jurnal Ilmu Komunikasi dan Ilmu Komputer Prima. Vol 3, No 1. 2019. Hal 17.

Budi santoso. "Bahasa dan Identitas Budaya". Sabda. Vol 1, No 1. 2006. Hal 45.

Dewi Yuliati.'Kebudayaan Lokal Versus Kebudayaan Global : Hidup atau Mati'. Jurnal Sejarah CITRA LEKHA. Vol 11 No 1. 2007. Hal 1.

Dokumen Kelurahan Simpang Baru, 2020.

Harahap, Toga dan Siahaan, Hotman. 1987. Orientasi Nilai-Nilai Budaya Batak Jakarta : Sanggar William Iskandar.

Hildigardis Nahak. 'Upaya Melestarikan Budaya Indonesia di Era Globalisasi'. Jurnal Sosiologi Nusantara. Vol 5, No 1. 2019. Hal 67.

Keberadaan Perda Syariah di Kota Serang”. Jurnal Penelitian Komunikasi dan Opino Publik. Vol 21, No 1. 2018. Hal 90.

Marbun, A dan Hutapea, T. 1987. Kamus Budaya Batak Toba. Jakarta : Balai Pustaka. 
Persepsi Generasi Muda Suku Batak di Kelurahan Simpang Baru Kota Pekanbaru Terhadap Tradisi Martarombo

(Grace Octaviani, Isjoni, Asyrul Fikri)

Sahrudin Pohan.'Tradisi Martutur Pada Masyarakat : Studi Kasus Masyarakat Desa Gunung Malintan”. Jurnal Education dan Development. Vol 7, No 3. 2019. Hal 353.

Sihombing, Toga. 1986. Filsafat Batak: Tentang Kebiasaan-Kebiasaan Adat Istiadat. Jakarta : Balai Pustaka.

Simanjuntak, Bungaran. 2011. Pemikiran Tentang Batak: Setelah 150 Tahun Agama Kristen di Sumatera Utara. Jakarta : Yayasan Pustaka Obor Indonesia.

Soemardjan, Selo dan Soemardi, Soelaeman. 1947. Setangkai Bunga Sosiologi. Jakarta : Yayasan Badan Penerbit Fakultas Ekonomi Universitas Indonesia.

Sugiyarto. "Menyimak (Kembali) Integrasi Budaya di Tanah Batak Toba". Jurnal Ilmiah Kajian Antropologi. Vol . Hal 35.

Sumantri, H. E. 2014. Generasi dan Generasi Muda. (Tangerang Selatan : Universitas Terbuka. 